\title{
Adjuvant Administration of Vitamin C Improves Mortality of Patients with Sepsis and Septic Shock: A Systems Review and Meta-Analysis
}

\author{
Jincan Lin*, Hua Li*, Yan Wen, Minwei Zhang\# \\ The First Affiliated Hospital, Xiamen University, Xiamen, China \\ Email: ${ }^{*}$ zmwicu@126.com
}

How to cite this paper: Lin, J.C., Li, H., Wen, Y. and Zhang, M.W. (2018) Adjuvant Administration of Vitamin C Improves Mortality of Patients with Sepsis and Septic Shock: A Systems Review and Meta-Analysis. Open Journal of Internal Medicine, 8, 146-159.

https://doi.org/10.4236/ojim.2018.82015

Received: April 12, 2018

Accepted: June 18, 2018

Published: June 21, 2018

Copyright (c) 2018 by authors and Scientific Research Publishing Inc. This work is licensed under the Creative Commons Attribution International License (CC BY 4.0).

http://creativecommons.org/licenses/by/4.0/

\begin{abstract}
The aim of this study was to examine whether vitamin C reduced mortality when adjutant therapy of patients with septic shock and severe sepsis compared with placebo by meta-analysis. Eligible trials were identified from Pubmed, Embase, Ovid, and the Cochrane database. Four randomized controlled trials (RCT) and two retrospective studies were published between 2000 and 2017 met the inclusion criteria and suitable for meta-analysis. The data were analyzed with randomized-effects or fixed-effects models using Review Manager Version 5.3. Four randomized studies with a total of 109 participants were suitable for meta-analysis. The heterogeneity was assessed by calculating the $\mathrm{Q}$ and $I^{2}$ methods. A random-effects approach instead of a fixed-effects analysis was undertaken if $I^{2}>50 \%$. Adjuvant vitamin $\mathrm{C}$ did not associate with a reduction in mortality as compared with placebo, it is occurred similarly in both RCT studies and retrospective studies. However, high doses of vitamin C ( $>50 \mathrm{mg} / \mathrm{kg} /$ day) significant reduced the mortality rate of severe sepsis patients. And administration of high doses of vitamin $\mathrm{C}$ to therapy severe sepsis did not significantly reduce the ICU length of stay. The results suggested a trend toward reducing mortality in severe sepsis and septic shock patients' adjuvant with vitamin C. Further multicenter large randomized controlled trials are necessary to determine the potential benefits of vitamin $\mathrm{C}$ in patients with severe sepsis and septic shock.
\end{abstract}

\section{Keywords}

Sepsis, Septic Shock, Vitamin C, Ascobic Acid, Mortality

\section{Introduction}

Sepsis is a serious and life-threatening medical condition, affecting approx${ }^{\star}$ Contributed equally. 
imately 26 million people worldwide every year [1]. Sepsis is caused by a dysregulated host with response to infection [2] [3] [4]. Despite multiple supportive therapies, death or disability often occurs in patients. Sepsis has become a major public health issue. The mortality of severe sepsis reaches up to almost $50 \%$ in patients that presents with septic shock [5]. Over the past decades, there has been a focus on searching for a new agent that can successful in directly targeting the pathophysiologic effects of sepsis. We have researched many immunomodulators such as: anti-tumornecrosis antibodies, and anti-TNF receptor antibodies, but these immunomodulators all failed to improve 28-day mortality in sepsis patients [6]. Furthermore, we have examined human activated protein $\mathrm{C}$, which can prevent microvascular dysfunction that contributes to multisystem organ failure in sepsis. However, it was found no improvement in outcomes later [7].

It is known that the pro-inflammatory mediators and oxidative stress play an important role in the pathogenesis and high morbidity and mortality associated with sepsis. When sepsis happened overwhelming oxidative stress and pro-inflammatory mediators are generated [8]. Which can increase endothelial permeability [9] and impairment of microcirculatory flow [10], contributing to organ dysfunction. However, current bundle care treatment protocols do not target the inflammatory and oxidative stress caused by sepsis [5]. Hence, there is a need for effective, targeted adjuvant therapies that reverse the inflammatory and oxidative stress present in sepsis patients.

Vitamin C, is a water-soluble vitamin that acts as an antioxidant and a cofactor for several enzymes in the body [11]. It can mitigate ROS-induced damage to endothelial and myocardial cells in ischemia/reperfusion. Therefore vitamin C might improve tissue perfusion and reduce tissue hypoxia and organ dysfunction by limiting endothelial dysfunction [12] [13]. Vitamin C also plays an important in the synthesis of catecholamines and other hormones important for the maintenance of adequate perfusion [14]. Additionally, vitamin C plays an important role in immune function, including influences macrophage activity, improves chemotaxis and supports lymphocytic proliferation [15]. Currently evidence is emerging that parenteral administration of vitamin $\mathrm{C}$ may be a beneficial adjuvant therapy of severe sepsis and septic shock in animal models.

And some studies have evaluated the effect of vitamin C supplementation in human severe sepsis. Fowler et al., [16] and Zabet et al., [17] found that intravenous infusion of vitamin $\mathrm{C}$ can prompt reduction of organ failure and reduce 28-day mortality. However, some experts have different opinions as follows: Ferrón-Celma et al., compared infusion of the vitamin C (450 mg/day) with placebo in a small cohort of patients with sepsis. At the end of the study, the mortality rate was $40 \%$ in the placebo group and $60 \%$ in the vitamin C-treated group [18]. Heyland D et al., found antioxidants (contain $1500 \mathrm{mg}$ vitamin C and mineral) shad no effect on 28-day mortality in critically ill patients which $32 \%$ are sepsis patients compared with placebo [19].

There have been controversial in administrate vitamin C for sepsis therapy. 
And there is still no Meta analysis to declare whether Vitamin C could reduce the mortality of patients with sepsis and septic shock. Accordingly, we conducted a meta-analysis to examine the effects on the adjuvant vitamin $\mathrm{C}$ to treat sepsis or septic shock.

\section{Methods}

\subsection{Study Selection}

We searched Medline, Embase, Ovid and Cochrane database. All databases were searched for articles published from inception until November 2017 using the following the same keywords as searching terms: sepsis, severe sepsis, septic shock, vitamin C, ascobic acid, ascobic, antioxidant. Reference lists of all retrieved articles were manually searched for further studies.

\subsection{Data Extraction}

Two reviewers (Zhang MW and Wen Y) independently extracted the following parameters from each study: first author, year of publication, study population characteristics, study design, number of patients, sex, age, inclusion and exclusion criteria, and rate of mortality in Table 1 . Disagreements between the two reviewers were resolved by consensus and discussion with a third reviewer. If there are confronted with the "same author" or "same data" issue, the latest published study was included.

\subsection{Inclusion and Exclusion Criteria}

We included trials with the following features:

1) Type of trials: randomized controlled clinical trials and retrospective studies.

2) Population: trials included adult population with sepsis or septic shock.

3) Intervention: patients submitted to vitamin $C$ for sepsis therapy.

4) Comparison: placebo for sepsis therapy.

5) Outcome: the primary outcome was 28 -day mortality.

Trials with the following features were excluded:

1) They were not published in English.

2) They were not published as original articles.

3) They did not use adult patients.

4) They did not administrate vitamin $C$ for sepsis therapy.

5) They included no data on mortality in patients with sepsis or septic shock.

6) Full-text articles were not available.

\subsection{Quality Assessment}

The quality of each article was assessed by two reviewers independently. Disagreements were resolved by consulting a third reviewer. The five-point Jadad scale was calculated to assess the quality of the RCTs studies [20]. This scale includes the method of randomization, blinding, and loss to follow-up (Table 2). 
Table 1. Characteristics of analysed studies. NA, non-available; RCT, randomized controlled trial; SD, standard deviation. Data are shown as mean \pm SD.

\begin{tabular}{|c|c|c|c|c|c|c|}
\hline Author & $\begin{array}{l}\text { Zabet } \\
\text { et al. }\end{array}$ & $\begin{array}{c}\text { Tanaka } \\
\text { et al. }\end{array}$ & Ferrón-Celma et al. & $\begin{array}{c}\text { Fowler } \\
\text { et al. }\end{array}$ & $\begin{array}{l}\text { Kahn } \\
\text { et al. }\end{array}$ & $\begin{array}{c}\text { Marik } \\
\text { et al. }\end{array}$ \\
\hline Type of study & RCT & RCT & RCT & RCT & Retrospective & Retrospective \\
\hline Year & 2016 & 2000 & 2009 & 2014 & 2011 & 2017 \\
\hline Country & IRAN & JAPAN & SPAIN & USA & USA & USA \\
\hline $\begin{array}{c}\text { Number of } \\
\text { patients }\end{array}$ & 28 & 37 & 20 & 24 & 40 & 94 \\
\hline Mean age \pm SD (years) & $64 \pm 16$ & $40 \pm 20$ & $68 \pm 4.5$ & NA & $42 \pm 16$ & $54 \pm 14$ \\
\hline Males/females (no.) & $21 / 7$ & $25 / 12$ & $11 / 9$ & $13 / 11$ & $33 / 0$ & $50 / 44$ \\
\hline Study quality & 4 stars & 3 stars & 4 stars & 5 stars & 7 stars & 7 stars \\
\hline
\end{tabular}

NA, non-available; RCT, randomized controlled trial; SD, standard deviation.

Table 2. Clinical background of RCT studies included in the meta-analysis.

\begin{tabular}{|c|c|c|c|c|c|c|c|}
\hline Author & $\begin{array}{l}\text { Sequences } \\
\text { generation }\end{array}$ & $\begin{array}{l}\text { Allocation } \\
\text { concealment }\end{array}$ & $\begin{array}{l}\text { Blinding of } \\
\text { participants and } \\
\text { researchers }\end{array}$ & $\begin{array}{l}\text { Blinding of } \\
\text { outcome } \\
\text { assessment }\end{array}$ & $\begin{array}{c}\text { Incomplete } \\
\text { outcome data }\end{array}$ & $\begin{array}{l}\text { Selective } \\
\text { reporting }\end{array}$ & Other bias \\
\hline Zabet, et al. & low & low & low & low & low & low & low \\
\hline $\begin{array}{c}\text { Tanaka } \mathrm{H} \\
\text { et al. }\end{array}$ & unclear & high & high & high & low & low & low \\
\hline Ferrón-Celma et al. & unclear & low & high & high & low & low & low \\
\hline Fowler et al. & low & low & low & low & low & low & low \\
\hline
\end{tabular}

And we judged retrospective studies with Newcastle-Ottawa scale [21]. We considered it to be at low risk of bias when received a score of nine or eight stars, studies that scored seven or six stars were regarded as medium risk, and scores below six were considered to be high risk of bias. This scale includes the method of randomization, blinding, and loss to follow-up which could be found in Table 2.

\subsection{Statistical Analysis}

We conducted a meta-analysis of the RCTs and retrospective studies, which were compared with clinical outcomes of septic shock patient, using either with vitamin $\mathrm{C}$ or placebo for therapy protocol. The primary outcomes of our analysis were mortality rate, secondary outcomes were ICU length of stay. Because of the inherent difference was significant in study design, we conducted separate meta-analyses for the RCTs and the retrospective studies. Given the inherent difference in the doses of vitamin $\mathrm{C}$ for adjuvant therapy of septic shock, we conducted separate meta-analyses for the low doses and high doses vitamin C. For mortality, some studies used 28-day mortality, whereas others used in hospital mortality. Given the observed heterogeneity in the study methods, we used ran- 
dom effects with meta-analyses to obtain primary main clinical outcomes. Data were analyzed by Review Manager (Version 5.3, the Nordic Cochrane Centre, Copenhagen, Denmark). The pooled odds ratio (OR) for dichotomous data and mean differences for continuous data with 95\% confidence intervals (CIs) were calculated. The statistical heterogeneity was explored and quantified using the Mantel-Haenszel chi-square test and the $P^{2}$ test. Heterogeneity was predefined as $P<0.05$ with the Mantel-Haenszel chi-square test or an $P^{2}$ value $>50 \%$. The random-effects model was used when heterogeneity was observed. Otherwise, the fixed-effects model was used. $P<0.05$ was considered statistically significant.

\section{Results}

\subsection{Eligible Studies}

A total of 4918 reports were identified through the initial search, and 4876 reports were excluded is browsing through the abstract. The remainder of the 42 records was examined in detail. In total, six studies were included that were compared with or without vitamin $\mathrm{C}$ for septic adjuvant therapy. In the included trails, four RCT and two retrospective studies were published between 2000 and 2017, which met the inclusion criteria and were suitable for meta-analysis (Figure 1). The systemic inflammatory responses to septic insults and burn injury, and the main reason of cause death were multiorgan failure, thus we included two small studies in burn patients assessed the effect of high-dose vitamin C (66 mg/kg/hour). The characteristics of the included studies are summarized in Table 1.

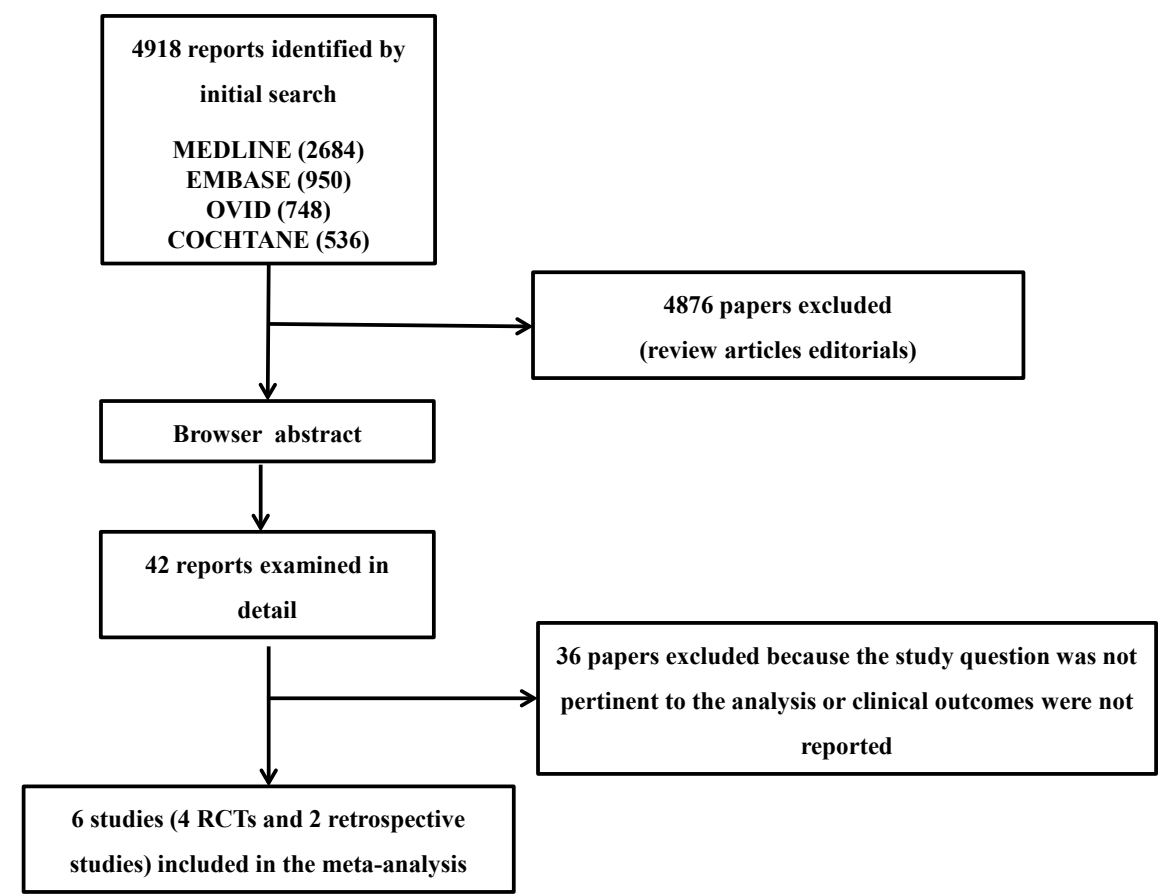

Figure 1. Selection of trials for inclusion in the meta-analysis, RCTs and randomized controlled trials. 


\subsection{Study Characteristics}

The main characteristics of the included studies are shown in Table 1. Overall, all included studies are small cohort of patients with septic shock. Sample size ranged from 20 to 37 , with a total of 109 participants.

\subsubsection{Mortality}

The effects of therapy with vitamin $\mathrm{C}$ on mortality in patients with severe sepsis were estimated from all six reports, and the heterogeneity was also determined to be significant $(P=0.04<0.05, P=58 \%)$. Thus, randomized-effects were used. The mortality rates in these six studies were explored including 28 day mortality or in hospital mortality. We found that adjuvant vitamin $\mathrm{C}$ does not associated with a reduction in mortality as compared placebo (OR 0.46, 95\% CI $0.17-1.24$, $P>0.05$ ), the similar situation was occurred in both RCT studies (OR $0.5395 \%$ CI $0.16-1.73, P>0.05$ ) and retrospective studies (OR 0.39, 95\% CI 0.04 - 3.64, $P>0.05$ ) (Figure 2).

\subsubsection{The Therapy Effects of the Doses of Vitamin C to Severe Sepsis}

The impact of different doses of vitamin $\mathrm{C}$ on mortality in patients with severe sepsis was calculated from four RCTs (Figure 3 ). The heterogeneity was determined to be non-significant $\left(P=0.18, I^{2}=36 \%<50 \%\right)$. Then fixed-effects were chosen. Compared with placebo, high doses of vitamin C (>50 mg/kg/day) significantly reduced the severe sepsis patients' mortality rate (OR 0.39, 95\% CI $0.16-0.94, P<0.05)$.

\subsubsection{The Effect of High Doses of Vitamin C on ICU Length of Stay}

The impact of vitamin C on ICU length of stay in patients with septic shock compared with placebo was estimated from two trails (Figure 4). The heterogeneity was determined to be non-significant $\left(P=0.56, I^{2}=0 \%\right)$. We found a trend toward reduced ICU length of stay in severe sepsis patients adjuvant with vitamin C compared with placebo. However, the result was not statistically significant (OR 1.46, 95\% CI $4.91-1.98, P>0.05$ ).

\subsection{Heterogeneity Analysis}

Tests for heterogeneity were performed for each of the clinical endpoints using the $P^{2}$ statistic. Heterogeneity was predefined as $P<0.05$ with the $I^{2}$ value $>50 \%$. The random-effects model was used if heterogeneity was observed. Otherwise, the fixed-effects model was used. $P<0.05$ was considered statistically significant. A funnel plot of the studies included in the meta-analysis reporting on overall morbidity is shown in Figure 5. A funnel plot of the RCT studies, which was reported on overall morbidity, is shown by using the meta-analysis. None of the studies laid outside the limits of the $95 \%$ CI, and there was no evidence of publication bias.

\section{Discussions}

It was reported that the mortality of severe sepsis without shock was about $14 \%$ 
to $30 \%$. However, the mortality raised to $22 \%$ to $40 \%$ in septic shock [22]. As recommended by the Surviving Sepsis Campaign [23], the mainstay of sepsis

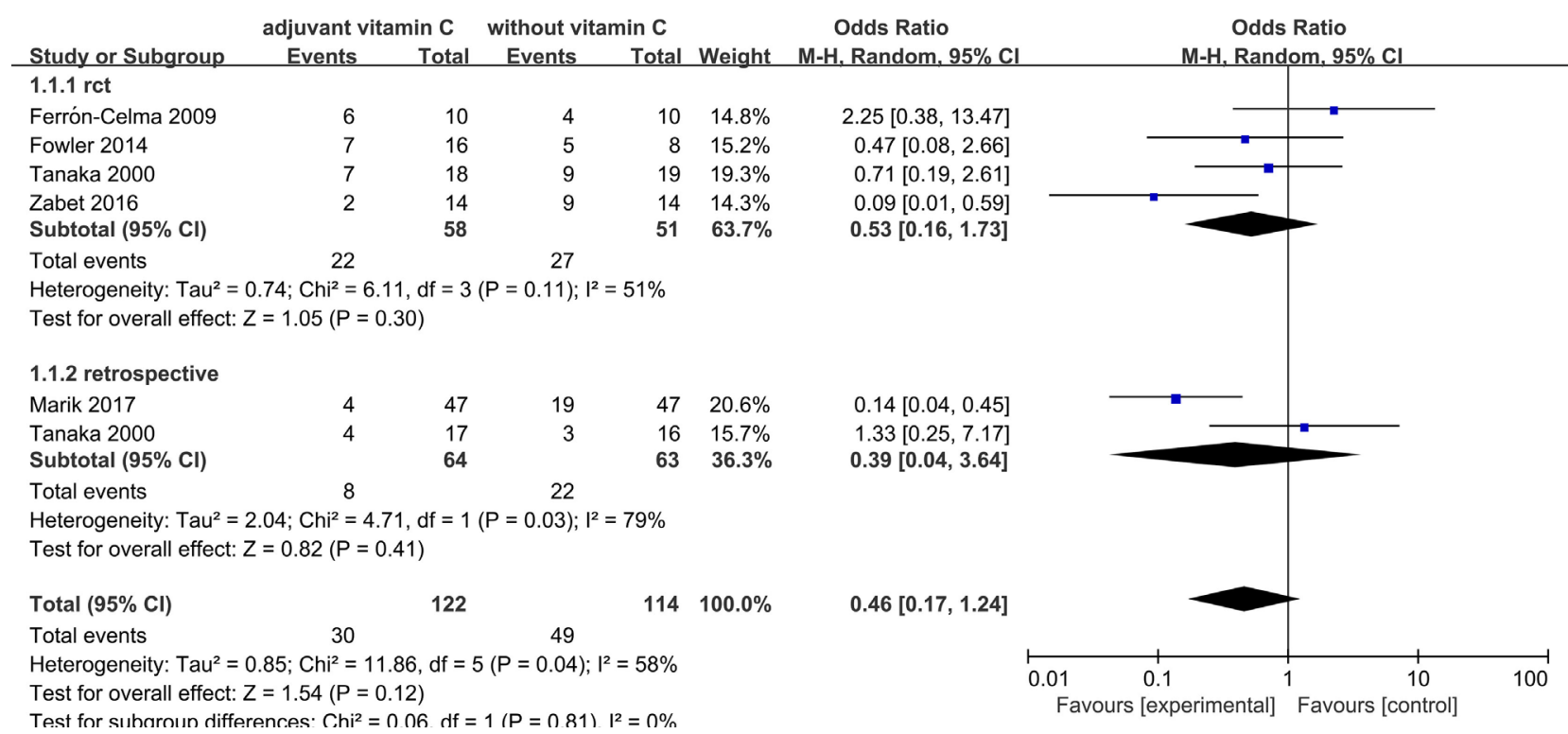

Figure 2. Results of the meta-analysis on mortality.

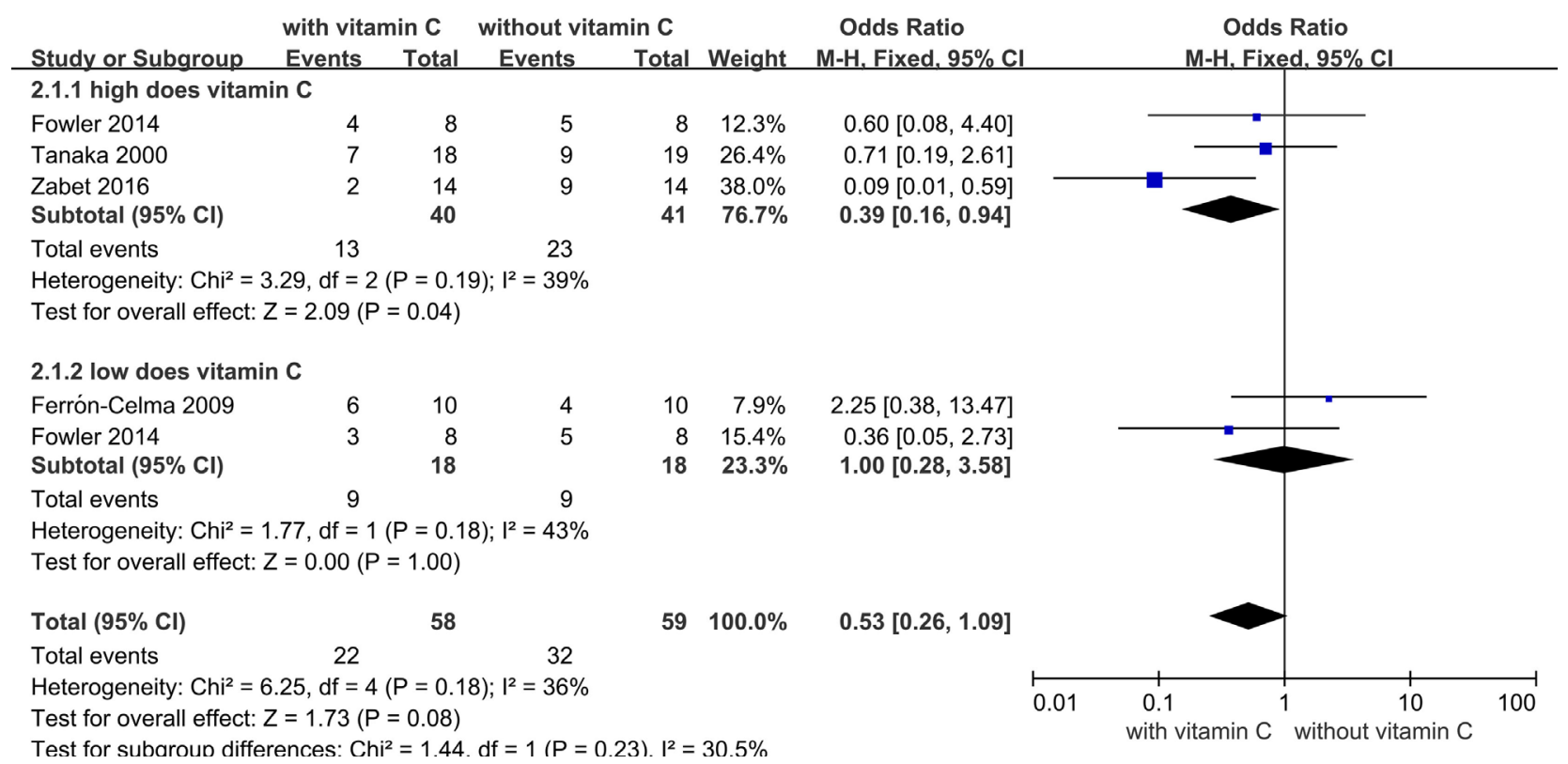

Figure 3. Results of the meta-analysis on the mortality of different doses vitamin $\mathrm{C}$ to treat severe sepsis.

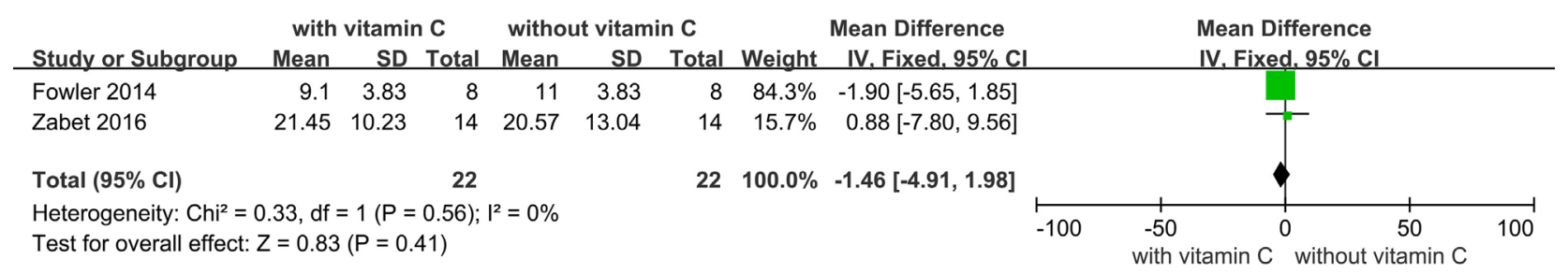

Figure 4. Results of the meta-analysis on the ICU length of stay. 


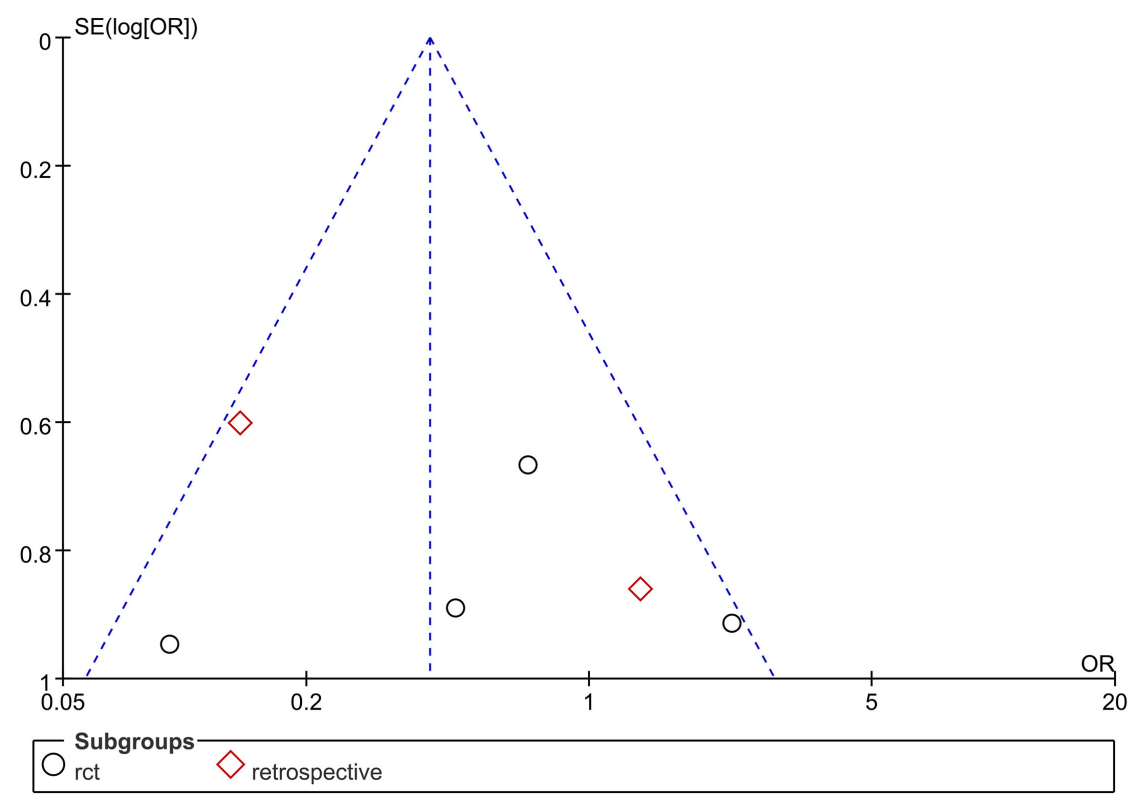

(a)

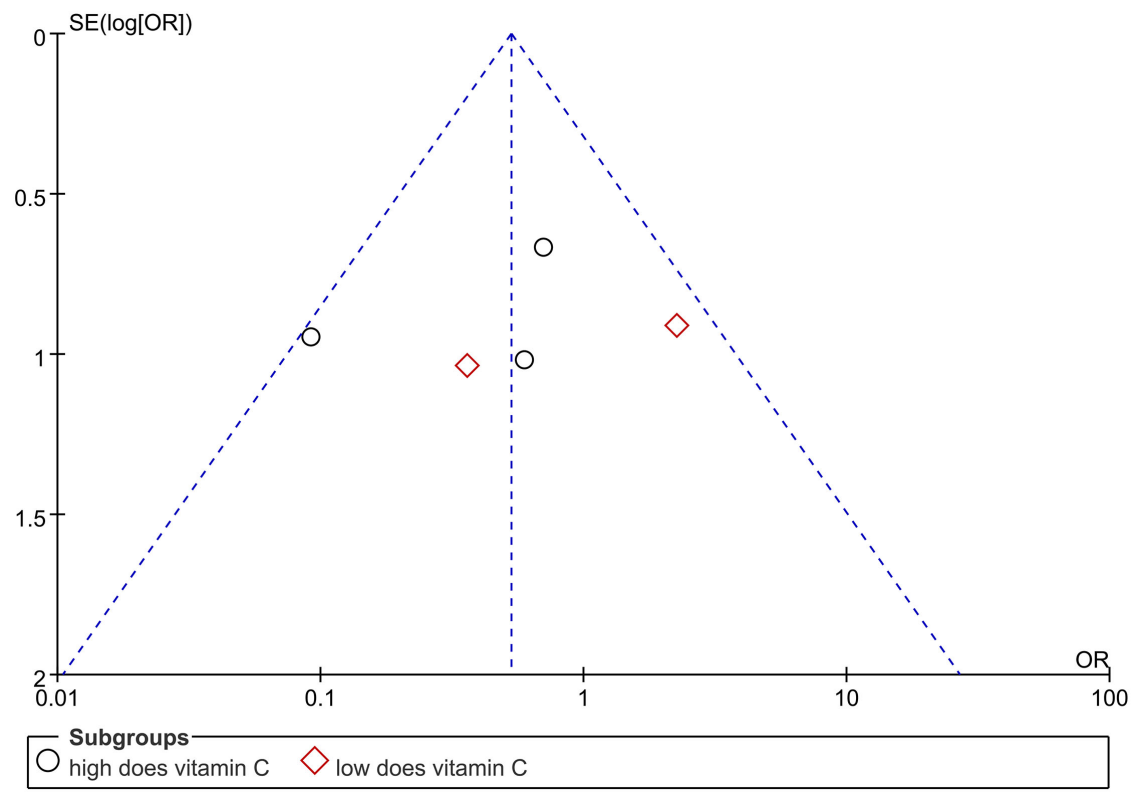

(b)

Figure 5. (a) Funnel plot of the all studies reporting on overall morbidity is shown included in the meta-analysis; (b) Funnel plot of the RCT studies reporting on overall morbidity is shown included in the meta-analysis.

treatment is directed at early identification and treatment of infection through antibiotic administration and source control, as well as reversing hemodynamic instability through fluid resuscitation and using vasopressors. However, sepsis remains a major cause of death and long-term disability despite multiple supportive therapies. Poor outcome is associated with ascorbate depletion, ROS, microvascular endothelial cells, and microvascular dysfunction [5]. Some researchers suggested that microvascular dysfunction plays the most important 
role in the deaths of septic patients [24]. As such, vitamin C was promoted as adjuvant therapy in conditions characterized by prevents or even reverses these pathological changes.

Evidences are emerging that administration of vitamin $\mathrm{C}$ may be a beneficial adjuvant therapy of severe sepsis and septic shock in animal models. For example, Fisher et al., found vitamin C deficient mice were easy to develop sepsis-induced multiple organ dysfunction and parenteral infusion, and ascorbic acid can reverse these injuries [25]. For example, injection of ascorbate or dehydroabietic acid (DHAA, the oxidized state of vitamin C, $200 \mathrm{mg} / \mathrm{kg}$ ) increases the survival in mice that occurred with septic shock by exposure to lipopolysaccharide (LPS) [26]. Similarly, injection of DHAA (200 mg/kg) also significantly ameliorated survival in fecal stem solution injection into peritoneum (FIP) mice [27]. Moreover, in an animal study, mice with vitamin C deficiency had an three folds mortality from Klebsiella pneumonia infection versus those administrated with ascorbate [28]. Additionally, vitamin C has shown to attenuate LPS mediated lung injury during sepsis in mouse model [26].

These robust experimental benefits are only derived from studies of mice but not human beings. There are little controlled studies on the effects of vitamin C on sepsis and septic shock patients. Fowler et al., studied the intravenous supplemented of 50 or $200 \mathrm{mg} / \mathrm{kg} /$ day ascorbic acid in patients with severe sepsis. As compared with placebo, patients who received ascorbic acid prompted reduction of organ failure, exhibited less inflammation and ameliorated 28-day mortality [17]. Zabet et al., studied infusion of $25 \mathrm{mg} / \mathrm{kg}$ ascorbic acid every 6 hours for 72 hours compared with placebo in the patients with septic shock who required norepinephrine treatment. The results have shown that mean dose of norepinephrine, duration of norepinephrine infusion and 28-day mortality were significantly decreased in the ascorbic acid than in the placebo [16]. Recently, Marik et al., examined the role of vitamin C combined with hydrocortisone and thiamine in patients with sepsis. The mortality of the treatment group significantly reduced compared with matched controls. Patients who received vitamin $\mathrm{C}$ have lower rates of acute kidney injury and a more rapid reduction in sequential organ failure assessment (SOFA) scores [29].

Schorah et al., found that plasma ascorbic concentrations keep at a very low level though supplement of low doses ascorbic (200 mg/day) in sepsis or traumatic injury patients [30]. And we found blood ferritin, redox-reactive iron, and ascorbate oxidation rate are significantly elevated in septic patients, and then reflected the accelerated destruction of ascorbate [31] [32]. Supplementation of the high dose of ascorbate can restore plasma ascorbate concentrations to normal level in septic patients. The results of our meta-analysis also shown that high doses of vitamin $\mathrm{C}$ can reduce the mortality of septic patients, but this effects did not occur in low doses vitamin $\mathrm{C}$ group. However, the high doses of vitamin $\mathrm{C}$ remain undetermined. Under normal physiological conditions, 100 to $300 \mathrm{mg}$ vitamin C per day can normalize plasma ascorbate [33]. Infusion $1000 \mathrm{mg} /$ day, 
but not $300 \mathrm{mg} /$ day of vitamin $\mathrm{C}$ can restore plasma ascorbate concentrations to normal in critically ill patients [34]. Because of the ascorbate repletion in septic patients, up to $3 \mathrm{~g}$ ( $50 \mathrm{mg} / \mathrm{kg} /$ day) daily is needed to restore normal plasma concentrations [34]. Thus, we defined the dose of $50 \mathrm{mg} / \mathrm{kg} /$ day as a cutoff point for low and high doses in our meta-analysis.

What needs to be pointed out that there is a main potential adverse effect with a long time of using high-dose vitamin $\mathrm{C}$, that is formation of calcium-oxalate stones in the kidneys [35]. However, this adverse effect never mentioned in our included six studies. The reason maybe is septic patients only require high-dose vitamin $\mathrm{C}$ therapy for a few days until source control and hemodynamic stability. And there has reported that it is scarce formation of calcium oxalate stones in the kidneys if you with a normal renal function [36]. And we recommend intravenous injection vitamin $C$ to replacement oral for high oral intake causes diarrhea [37]. Additionally, in patients with glucose-6-phosphate dehydrogenase deficiency infusion high-dose ascorbate may cause intravascular hemolysis [38]. Therefore, it is wise to avoid administration of high doses of vitamin $\mathrm{C}$ in patients with renal dysfunction or glucose-6-phosphate dehydrogenase deficiency. Do not use vitamin $C$ for a long time in patients, and the best way to administrate vitamin $\mathrm{C}$ is intravenous injection.

The results of this meta-analysis should be interpreted with caution for several reasons. Firstly, all of the data in the present study come from low sample size of studies, and the overall level of clinical evidence is not sufficient. Secondly, the most trials included were sever sepsis or septic shock patients, whereas one trial was burn injury patients. Even though there existed similarities between the systemic inflammatory responses to septic insults and burn injury, and the main reason cause death were multiorgan failure, the results were potentially heterogeneity i [18]. Moreover, different doses of vitamin C were used, oral and intravenous vitamin $C$ regimens were mixed. Thus, those results related with vitamin $\mathrm{C}$ were potentially overstated. Finally, some of the trials included 28-day mortality values, whereas one trial only reported mortality, thus various time points may influence the overall results extrapolation.

\section{Conclusion}

To our knowledge, no meta-analysis has compared with vitamin $\mathrm{C}$ or placebo to treat sepsis patients up to now. In this meta-analysis, the treatment of vitamin $\mathrm{C}$ as a novel adjuvant therapy on mortality in severe sepsis and septic shock was investigated. The result has shown that high doses of vitamin $C$ ( $>50 \mathrm{mg} / \mathrm{kg} /$ day) significant reduce the mortality rate of severe sepsis patients. However, low doses of vitamin $\mathrm{C}$ have no effect on the mortality. Administration of high doses vitamin $\mathrm{C}$ was not significant reduce ICU length of stay in septic patients. In the future, a large multicenter randomized controlled trial is necessary to determine the potential benefits of vitamin $\mathrm{C}$ in patients with severe sepsis and septic shock. 


\section{Fund}

Minwei Zhang is supported by the Fujian Provincial Natural Science Foundation of China (No. 2015101556).

\section{Declaration of Conflict of Interest}

The remaining authors have no financial relationships to disclose and no conflicts of interest to report.

\section{References}

[1] Teng, J., Pourmand, A. and Mazer-Amirshahi, M. (2017) Vitamin C: The Next Step in Sepsis Management? Journal of Critical Care, 43, 230-234. https://doi.org/10.1016/j.jcrc.2017.09.031

[2] Singer, M., Deutschman, C.S., Seymour, C.W., Shankar-Hari, M., Annane, D., Bauer, M., Bellomo, R., Bernard, G.R., Chiche, J.D., Coopersmith, C.M., Hotchkiss, R.S., Levy, M.M., Marshall, J.C., Martin, G.S., Opal, S.M., Rubenfeld, G.D., van der Poll, T., Vincent, J.L. and Angus, D.C. (2016) The Third International Consensus Definitions for Sepsis and Septic Shock (Sepsis-3). JAMA, 315, 801-810. https://doi.org/10.1001/jama.2016.0287

[3] Shankar-Hari, M., Phillips, G.S., Levy, M.L., Seymour, C.W., Liu, V.X., Deutschman, C.S., Angus, D.C., Rubenfeld, G.D., Singer, M. and Sepsis Definitions Task, F. (2016) Developing a New Definition and Assessing New Clinical Criteria for Septic Shock: For the Third International Consensus Definitions for Sepsis and Septic Shock (Sepsis-3). JAMA, 315, 775-787. https://doi.org/10.1001/jama.2016.0289

[4] Seymour, C.W., Liu, V.X., Iwashyna, T.J., Brunkhorst, F.M., Rea, T.D., Scherag, A., Rubenfeld, G., Kahn, J.M., Shankar-Hari, M., Singer, M., Deutschman, C.S., Escobar, G.J. and Angus, D.C. (2016) Assessment of Clinical Criteria for Sepsis: For the Third International Consensus Definitions for Sepsis and Septic Shock (Sepsis-3). $J A M A, 315,762-774$. https://doi.org/10.1001/jama.2016.0288

[5] Wilson, J.X. (2013) Evaluation of Vitamin C for Adjuvant Sepsis Therapy. Antioxidants \& Redox Signaling, 19, 2129-2140. https://doi.org/10.1089/ars.2013.5401

[6] Seeley, E.J. and Bernard, G.R. (2016) Therapeutic Targets in Sepsis: Past, Present, and Future. Clinics in Chest Medicine, 37, 181-189. https://doi.org/10.1016/j.ccm.2016.01.015

[7] Bernard, G.R., Vincent, J.L., Laterre, P.F., La Rosa, S.P., Dhainaut, J.F., Lopez-Rodriguez, A., Steingrub, J.S., Garber, G.E., Helterbrand, J.D., Ely, E.W., Fisher Jr., C.J. and Recombinant Human Protein CWEiSSsg (2001) Efficacy and Safety of Recombinant Human Activated Protein C for Severe Sepsis. New England Journal of Medicine, 344, 699-709. https://doi.org/10.1056/NEJM200103083441001

[8] Oudemans-van Straaten, H.M., Spoelstra-de Man, A.M. and de Waard, M.C. (2014) Vitamin C Revisited. Critical Care, 18, 460. https://doi.org/10.1186/s13054-014-0460-X

[9] Wilson, J.X. (2009) Mechanism of Action of Vitamin C in Sepsis: Ascorbate Modulates Redox Signaling in Endothelium. Biofactors, 35, 5-13. https://doi.org/10.1002/biof.7

[10] Chen, Y.H., Lin, S.J., Chen, Y.L., Liu, P.L. and Chen, J.W. (2006) Anti-Inflammatory Effects of Different Drugs/Agents with Antioxidant Property on Endothelial Expression of Adhesion Molecules. Cardiovascular \& Hematological Disorders Drug 
Targets, 6, 279-304. https://doi.org/10.2174/187152906779010737

[11] Koekkoek, W.A. and van Zanten, A.R. (2016) Antioxidant Vitamins and Trace Elements in Critical Illness. Nutrition in Clinical Practice, 31, 457-474. https://doi.org/10.1177/0884533616653832

[12] May, J.M. (2000) How Does Ascorbic Acid Prevent Endothelial Dysfunction? Free Radical Biology and Medicine, 28, 1421-1429. https://doi.org/10.1016/S0891-5849(00)00269-0

[13] Shaik-Dasthagirisaheb, Y.B., Varvara, G., Murmura, G., Saggini, A., Caraffa, A., Antinolfi, P., Tete, S., Tripodi, D., Conti, F., Cianchetti, E., Toniato, E., Rosati, M., Speranza, L., Pantalone, A., Saggini, R., Tei, M., Speziali, A., Conti, P., Theoharides, T.C. and Pandolfi, F. (2013) Role of Vitamins D, E and C in Immunity and Inflammation. Journal of Biological Regulators and Homeostatic Agents, 27, 291-295.

[14] Honore, P.M., Jacobs, R., Hendrickx, I., De Waele, E. and Spapen, H.D. (2016) Adjuvant Vitamin C Treatment in Sepsis-How Many Oranges a Day Keep (Vasopressor-Dependent) Septic Shock Away? Journal of Thoracic Disease, 8, E993-E995. https://doi.org/10.21037/jtd.2016.08.60

[15] Rudiger, A. and Singer, M. (2007) Mechanisms of Sepsis-Induced Cardiac Dysfunction. Critical Care Medicine, 35, 1599-1608. https://doi.org/10.1097/01.CCM.0000266683.64081.02

[16] Zabet, M.H., Mohammadi, M., Ramezani, M. and Khalili, H. (2016) Effect of High-Dose Ascorbic Acid on Vasopressor's Requirement in Septic Shock. Journal of Research in Pharmacy Practice, 5, 94-100. https://doi.org/10.4103/2279-042X.179569

[17] Fowler, A.A., Syed, A.A., Knowlson, S., Sculthorpe, R., Farthing, D., DeWilde, C., Farthing, C.A., Larus, T.L., Martin, E., Brophy, D.F., Gupta, S., Medical Respiratory Intensive Care Unit Nursing, Fisher, B.J. and Natarajan, R. (2014) Phase I Safety Trial of Intravenous Ascorbic Acid in Patients with Severe Sepsis. Journal of Translational Medicine, 12, 32. https://doi.org/10.1186/1479-5876-12-32

[18] Ferron-Celma, I., Mansilla, A., Hassan, L., Garcia-Navarro, A., Comino, A.M., Bueno, P. and Ferron, J.A. (2009) Effect of Vitamin C Administration on Neutrophil Apoptosis in Septic Patients after Abdominal Surgery. Journal of Surgical Research, 153, 224-230. https://doi.org/10.1016/j.jss.2008.04.024

[19] Heyland, D., Muscedere, J., Wischmeyer, P.E., Cook, D., Jones, G., Albert, M., Elke, G., Berger, M.M. and Day, A.G., for the Canadian Critical Care Trials Group. (2013) A Randomized Trial of Glutamine and Antioxidants in Critically Ill Patients. New England Journal of Medicine, 368, 1489-1497. https://doi.org/10.1056/NEJMoa1212722

[20] Jadad, A.R., Moore, R.A., Carroll, D., Jenkinson, C., Reynolds, D.J., Gavaghan, D.J. and McQuay, H.J. (1996) Assessing the Quality of Reports of Randomized Clinical Trials: Is Blinding Necessary? Controlled Clinical Trials, 17, 1-12. https://doi.org/10.1016/0197-2456(95)00134-4

[21] Stang, A. (2010) Critical Evaluation of the Newcastle-Ottawa Scale for the Assessment of the Quality of Nonrandomized Studies in Meta-Analyses. European Journal of Epidemiology, 25, 603-605. https://doi.org/10.1007/s10654-010-9491-Z

[22] Kaukonen, K.M., Bailey, M., Suzuki, S., Pilcher, D. and Bellomo, R. (2014) Mortality Related to Severe Sepsis and Septic Shock among Critically Ill Patients in Australia and New Zealand, 2000-2012. JAMA, 311, 1308-1316. https://doi.org/10.1001/jama.2014.2637

[23] Rhodes, A., Evans, L.E., Alhazzani, W., Levy, M.M., Antonelli, M., Ferrer, R., Ku- 
mar, A., Sevransky, J.E., Sprung, C.L., Nunnally, M.E., Rochwerg, B., Rubenfeld, G.D., Angus, D.C., Annane, D., Beale, R.J., Bellinghan, G.J., Bernard, G.R., Chiche, J.D., Coopersmith, C., De Backer, D.P., French, C.J., Fujishima, S., Gerlach, H., Hidalgo, J.L., Hollenberg, S.M., Jones, A.E., Karnad, D.R., Kleinpell, R.M., Koh, Y., Lisboa, T.C., Machado, F.R., Marini, J.J., Marshall, J.C., Mazuski, J.E., McIntyre, L.A., McLean, A.S., Mehta, S., Moreno, R.P., Myburgh, J., Navalesi, P., Nishida, O., Osborn, T.M., Perner, A., Plunkett, C.M., Ranieri, M., Schorr, C.A., Seckel, M.A., Seymour, C.W., Shieh, L., Shukri, K.A., Simpson, S.Q., Singer, M., Thompson, B.T., Townsend, S.R., Van der Poll, T., Vincent, J.L., Wiersinga, W.J., Zimmerman, J.L. and Dellinger, R.P. (2017) Surviving Sepsis Campaign: International Guidelines for Management of Sepsis and Septic Shock: 2016. Intensive Care Medicine, 43, 304-377. https://doi.org/10.1007/s00134-017-4683-6

[24] Vincent, J.L., Nelson, D.R. and Williams, M.D. (2011) Is Worsening Multiple Organ Failure the Cause of Death in Patients with Severe Sepsis? Critical Care Medicine, 39, 1050-1055. https://doi.org/10.1097/CCM.0b013e31820eda29

[25] Fisher, B.J., Kraskauskas, D., Martin, E.J., Farkas, D., Puri, P., Massey, H.D., Idowu, M.O., Brophy, D.F., Voelkel, N.F., Fowler, A.A. and Natarajan, R. (2014) Attenuation of Sepsis-Induced Organ Injury in Mice by Vitamin C. Journal of Parenteral and Enteral Nutrition, 38, 825-839. https://doi.org/10.1177/0148607113497760

[26] Fisher, B.J., Seropian, I.M., Kraskauskas, D., Thakkar, J.N., Voelkel, N.F., Fowler, A.A. and Natarajan, R. (2011) Ascorbic Acid Attenuates Lipopolysaccharide-Induced Acute Lung Injury. Critical Care Medicine, 39, 1454-1460. https://doi.org/10.1097/CCM.0b013e3182120cb8

[27] Fisher, B.J., Kraskauskas, D., Martin, E.J., Farkas, D., Wegelin, J.A., Brophy, D., Ward, K.R., Voelkel, N.F., Fowler, A.A. and Natarajan, R. (2012) Mechanisms of Attenuation of Abdominal Sepsis Induced Acute Lung Injury by Ascorbic Acid. American Journal of Physiology-Lung Cellular and Molecular Physiology, 303, L20-L32. https://doi.org/10.1152/ajplung.00300.2011

[28] Gaut, J.P., Belaaouaj, A., Byun, J., Roberts, L.J., Maeda, N., Frei, B. and Heinecke, J.W. (2006) Vitamin C Fails to Protect Amino Acids and Lipids from Oxidation during Acute Inflammation. Free Radical Biology and Medicine, 40, 1494-1501.

https://doi.org/10.1016/j.freeradbiomed.2005.12.013

[29] Marik, P.E., Khangoora, V., Rivera, R., Hooper, M.H. and Catravas, J. (2017) Hydrocortisone, Vitamin C, and Thiamine for the Treatment of Severe Sepsis and Septic Shock: A Retrospective Before-After Study. Chest, 151, 1229-1238. https://doi.org/10.1016/j.chest.2016.11.036

[30] Schorah, C.J., Downing, C., Piripitsi, A., Gallivan, L., Al-Hazaa, A.H., Sanderson, M.J. and Bodenham, A. (1996) Total Vitamin C, Ascorbic Acid, and Dehydroascorbic Acid Concentrations in Plasma of Critically Ill Patients. American Journal of Clinical Nutrition, 63, 760-765. https://doi.org/10.1093/ajcn/63.5.760

[31] Galley, H.F., Davies, M.J. and Webster, N.R. (1996) Ascorbyl Radical Formation in Patients with Sepsis: Effect of Ascorbate Loading. Free Radical Biology and Medicine, 20, 139-143. https://doi.org/10.1016/0891-5849(95)02022-5

[32] Spada, P.L., Rossi, C., Alimonti, A., Bocca, B., Cozza, V., Ricerca, B.M., Bocci, M.G., Vulpio, C. and De Sole, P. (2008) Ferritin Iron Content in Haemodialysis Patients: Comparison with Septic and Hemochromatosis Patients. Clinical Biochemistry, 41, 997-1001. https://doi.org/10.1016/j.clinbiochem.2008.05.003

[33] Levine, M., Padayatty, S.J. and Espey, M.G. (2011) Vitamin C: A Concentration-Function Approach Yields Pharmacology and Therapeutic Discoveries. $A d$ vances in Nutrition, 2, 78-88. https://doi.org/10.3945/an.110.000109 
[34] Long, C.L., Maull, K.I., Krishnan, R.S., Laws, H.L., Geiger, J.W., Borghesi, L., Franks, W., Lawson, T.C. and Sauberlich, H.E. (2003) Ascorbic Acid Dynamics in the Seriously Ill and Injured. Journal of Surgical Research, 109, 144-148. https://doi.org/10.1016/S0022-4804(02)00083-5

[35] Thomas, L.D., Elinder, C.G., Tiselius, H.G., Wolk, A. and Akesson, A. (2013) Ascorbic Acid Supplements and Kidney Stone Incidence among Men: A Prospective Study. JAMA Internal Medicine, 173, 386-388.

https://doi.org/10.1001/jamainternmed.2013.2296

[36] Robitaille, L., Mamer, O.A., Miller, W.H., Levine, M., Assouline, S., Melnychuk, D., Rousseau, C. and Hoffer, L.J. (2009) Oxalic Acid Excretion after Intravenous Ascorbic Acid Administration. Metabolism, 58, 263-269.

https://doi.org/10.1016/j.metabol.2008.09.023

[37] Padayatty, S.J., Sun, H., Wang, Y., Riordan, H.D., Hewitt, S.M., Katz, A., Wesley, R.A. and Levine, M. (2004) Vitamin C Pharmacokinetics: Implications for Oral and Intravenous Use. Annals of Internal Medicine, 140, 533-537. https://doi.org/10.7326/0003-4819-140-7-200404060-00010

[38] Du, J., Cullen, J.J. and Buettner, G.R. (2012) Ascorbic Acid: Chemistry, Biology and the Treatment of Cancer. Biochimica et Biophysica Acta, 1826, 443-457. 